Brazilian Journal

of Chemical

Engineering

\title{
REMOVAL OF NITRATE FROM DRINKING WATER BY USING PdCu STRUCTURED CATALYSTS BASED ON CORDIERITE MONOLITHS
}

\author{
María A. Jaworski ${ }^{1,2^{*}}$, Bibiana P. Barbero ${ }^{3}$, Guillermo J. Siri ${ }^{1,2}$ and Mónica L. Casella ${ }^{1}$ \\ ${ }^{1}$ Universidad Nacional de La Plata, Facultad de Ciencias Exactas, Centro de Investigación y Desarrollo en Procesos Catalíticos, \\ La Plata. Argentina. E-mail: majaworski@quimica.unlp.edu.ar - ORCID: 0000-0003-0696-759X; ORCID: 0000-0003-4164-469X \\ ${ }^{2}$ Universidad Nacional de La Plata, Facultad de Ingeniería, Programa de Investigación y Desarrollo de Catalizadores, La Plata. Argentina. \\ ${ }^{3}$ Universidad Nacional de San Luis, Instituto de Investigaciones en Tecnología Química, San Luis, Argentina. ORCID: 0000-0003-1659-0271
}

(Submitted: July 2, 2018 ; Revised: October 28, 2018 ; Accepted: November 6, 2018)

\begin{abstract}
Structured catalysts were prepared, characterized and evaluated in $\mathrm{NO}_{3}^{-}$removal from drinking water. Different suspensions containing a previously optimized $\mathrm{PdCu} / 5 \mathrm{wt} \% \mathrm{ZrO}_{2}-\mathrm{Al}_{2} \mathrm{O}_{3}$ powder catalyst (hereinafter $\mathrm{PdCu} / 5 \mathrm{ZA}_{\mathrm{p}}$ ) were prepared and deposited on cordierite monoliths by washcoating. The effect of suspension concentration, the particle size, the immersion number, the use of suspension stabilizer agent, and an alumina precoating on the coating adherence and catalytic performance were studied. All the prepared structured catalysts were active for the elimination of $\mathrm{NO}_{3}^{-}$and presented good selectivity to $\mathrm{N}_{2}(>93 \%)$ in synthetic water samples. The catalyst performance was related to the amount of deposited catalyst. The highest activity and the best coating adherence were obtained with the structured catalyst prepared by a single immersion in a $14 \mathrm{wt} \%$ concentration suspension, which was obtained from the powder catalyst milled for $10 \mathrm{~h}$ and stabilized with colloidal alumina. This catalyst also showed good activity when it was reused for four cycles and when it was evaluated with real water samples.

Keywords: Water pollution; Nitrate; Cordierite monoliths; PdCu catalyst; Structured catalyst.
\end{abstract}

\section{INTRODUCTION}

Industrial and agricultural activities lead to the discharge of pesticides, fertilizers and organic wastes of animals and plants that contaminate the water in a diffuse but very remarkable way, in particular, groundwater. One of the most serious problems is the high levels of nitrate $\left(\mathrm{NO}_{3}^{-}\right.$) found in some groundwater reservoirs (Faridullah et al., 2017 ; Xu et al., 2017). When $\mathrm{NO}_{3}^{-}$levels in soil are greater than the ones plants can assimilate, irrigation and rainwater cause $\mathrm{NO}_{3}^{-}$to percolate and reach the groundwater. This fact affects the quality of life and health of a significant number of people, especially in areas dominated by agricultural activities (Zhai et al., 2017). Drinking water with excess $\mathrm{NO}_{3}^{-}$ion can be harmful because $\mathrm{NO}_{3}^{-}$is easily reduced to nitrite $\left(\mathrm{NO}_{2}^{-}\right)$in the mouth and intestines, causing methemoglobinemia, a conversion of hemoglobin to methemoglobin that depletes oxygen levels, particularly in children under 6 months (blue-baby syndrome). In addition, $\mathrm{NO}_{3}^{-}$is a precursor of carcinogenic nitrosamines (Zhai et al., 2017). The maximum contaminant level permitted by the US Environmental Protection Agency (EPA) is 10 ppm for $\mathrm{N}^{-\mathrm{NO}_{3}-}$ (expressed in terms of nitrogen $\mathrm{N}$ in $\mathrm{NO}_{3}^{-}$) in the water supply for the population (water.epa. gov/drink/contaminants/basicinformation/nitrate.cfm) .While for the World Health Organization (WHO) it is 50 ppm for $\mathrm{NO}_{3}^{-}$and 1 ppm for $\mathrm{NO}_{2}^{-}$(www.who.int/water sanitation_health/dwq/chemicals/nitratenitrite2ndadd. pdf).

In Argentina, the Argentine Food Code establishes a maximum concentration of $45 \mathrm{ppm}$ for $\mathrm{NO}_{3}^{-}$and $0.1 \mathrm{ppm}$ for $\mathrm{NO}_{2}^{-}$(www.anmat.gov.ar/alimentos/ normativas_alimentos_caa.asp).

\footnotetext{
* Corresponding author: María A. Jaworski - E-mail: majaworski@quimica.unlp.edu.ar
} 
There are different treatments for $\mathrm{NO}_{3}^{-}$removal from water such as electrodialysis, distillation, ion exchange, reverse osmosis, catalytic or electrochemical reduction, biological degradation, among others ( $\mathrm{Li}$ et al., 2017; Huo et al., 2017). For environmental reasons, the best technique to remove $\mathrm{NO}_{3}{ }^{-}$should convert it to gaseous $\mathrm{N}_{2}$. One of the most promising processes is the reduction of $\mathrm{NO}_{3}^{-}$to $\mathrm{N}_{2}$ using heterogeneous catalysts in the presence of $\mathrm{H}_{2}$ as a reducing agent (Huo et al., 2017; Mirabi et al., 2017). These catalysts generally contain a noble metal $(\mathrm{Pd}, \mathrm{Rh}, \mathrm{Ru}$ or $\mathrm{Pt})$ and a promoter metal $(\mathrm{Cu}, \mathrm{Ag}, \mathrm{Fe}, \mathrm{Hg}, \mathrm{Ni}, \mathrm{Cu}, \mathrm{Zn}, \mathrm{Sn}$ or In) (Ding et al., 2017; Zoppas et al., 2016; Kim et al., 2016; Martínez et al., 2017). In these catalysts, the bimetallic sites permit the reduction of $\mathrm{NO}_{3}^{-}$to $\mathrm{NO}_{2}^{-}$, which is then reduced to $\mathrm{N}_{2}$ or over-reduced to $\mathrm{NH}_{4}^{+}$ over the monometallic sites. This latter product is an inconvenient aspect of these systems (Hamid et al., 2018; Martínez et al., 2017).

The powder catalysts containing $\mathrm{PdCu}$ or $\mathrm{RhMo}$ as active phase supported on $\mathrm{Al}_{2} \mathrm{O}_{3}$ or $\mathrm{ZrO}_{2}$, both pure and mixtures of these supports, were previously evaluated in our group. These catalysts showed good catalytic performance in a batch reactor (Jaworski, et al., 2014; 2018). Particularly, it was found that the $\mathrm{PdCu}$ catalyst supported on $\mathrm{ZrO}_{2}-\mathrm{Al}_{2} \mathrm{O}_{3}$ showed good catalytic activity and $\mathrm{N}_{2}$ selectivity (Jaworski, et al., 2014). Despite the good activity and selectivity results obtained with these catalysts in a batch reactor, the use of a catalyst in a powder form is not technologically viable. The use of these catalysts could cause problems in their recovery, leading to the contamination of the treated water by metal particles. To avoid the loss of catalytic material, the use of pellets or extruded supports is proposed. A disadvantage of the use of pellets is that the diffusion of reagents and/or products into the pores of the catalysts would decrease the selectivity to $\mathrm{N}_{2}$ (Durkin et al., 2018; Zoppas et al., 2018).

The use of structured catalysts such as monoliths, foams and grids could overcome the limitations caused by the use of powder formulations (Durkin et al., 2018; Li et al. 2019; Muñoz-Murillo et al., 2018). Structured catalysts based on monoliths with different chemical composition are widely used, especially in environmental catalytic applications. For example, Ni-based catalysts $\left(\mathrm{Ni}-\mathrm{CeO}_{2}\right)$ prepared on ceramic monoliths have been obtained by dip-coating the support in an acid-free stable catalyst dispersion. The structured catalysts obtained were evaluated towards the biogas oxy-steam reforming reaction. The use of structured system instead of packed bed reactors allows one to obtain stable performances, in term of $\mathrm{CH}_{4}(97 \%)$ and $\mathrm{CO}_{2}(87 \%)$ conversion (Balzarotti et al., 2018).

Some of the structured catalysts used are supported on ceramic monoliths. These monoliths contain parallel channels of an inert oxide such as cordierite $\left(2 \mathrm{MgO}_{2} \cdot \mathrm{Al}_{2} \mathrm{O}_{3} \cdot 5 \mathrm{SiO}_{2}\right)$ and are coated with a thin layer of the catalyst (Özyönüm et al., 2016; Şem et al., 2016). Cordierite has numerous important applications due to its low cost, its excellent properties, such as low coefficient of thermal expansion, good thermal resistance, low dielectric constant, high chemical inertness, refractoriness and adequate mechanical properties (Labhsetwar et al., 2012; Yuan et al., 2016).

A series of copper/ceria washcoated cordierite monoliths was prepared and tested in the carbon monoxide preferential oxidation reaction. These catalysts were active in the $\mathrm{CO}-\mathrm{PROX}$ reaction and CO-PROX stage, and could be used in the case of nonstationary applications (Landi et al., 2016). Volatile organic compounds (VOCs) that are air pollutants released from many industrial operations were eliminated using a honeycomb monolith washcoated with $\mathrm{Mn}-\mathrm{M}$ mixed oxide $(\mathrm{M}=\mathrm{Cu}, \mathrm{Ni}$ or $\mathrm{Co}$ ) (Zhang and $\mathrm{Wu}, 2016$ ) or by using $\mathrm{Mn}, \mathrm{Ce}$ and $\mathrm{Ce} / \mathrm{Mn}$ supported ceramic monoliths with natural clays as raw materials (Colman-Lerner et al., 2016). Catalysts of $\mathrm{LaCoO}_{3} / \gamma-$ $\mathrm{Al}_{2} \mathrm{O}_{3} /$ cordierite monolith, $\mathrm{LaCoO}_{3} / \mathrm{SiO}_{2} /$ cordierite monolith and $\mathrm{LaCoO}_{3} / \mathrm{TiO}_{2} /$ cordierite monolith were used to reduce diesel particulate emissions that cause serious problems in human health (Tang et al., 2017).

Considering the advantages of the structured catalysts, in this work the preparation of cordierite monoliths coated with a powder catalyst previously optimized by our group is reported. The powder catalyst is $\mathrm{PdCu}$ supported on $\mathrm{Al}_{2} \mathrm{O}_{3}$ modified with 5 $\mathrm{wt} \% \mathrm{ZrO}_{2}\left(\mathrm{PdCu} / 5 \mathrm{ZA} \mathrm{A}_{\mathrm{p}}\right)$, which showed good catalytic performance in the $\mathrm{NO}_{3}^{-}$removal reaction (Jaworski, et al., 2014).

It has been shown that the adherence of the active phase to the monolith is essential in the development of structured catalysts (Ashraf et al., 2018; Sedjame et al., 2018). Different factors affect this adherence, such as the characteristics of the suspension containing the active phase, the particle size of the solid to be deposited on the monolith, the nature of the dispersion medium, the concentration of solids and $\mathrm{pH}$ of the suspension (Landi et al., 2016). For this reason, different suspensions of $\mathrm{PdCu} / 5 \mathrm{ZA}$ pere used for the washcoating of cordierite monoliths. The effects of the particle size, the solid concentration in the suspension, the addition of a suspension stabilizer, the number of immersions and the effect of a precoating on the adherence were studied. Furthermore, the catalytic performance for nitrate reduction in water was evaluated.

\section{MATERIALS AND METHODS}

\section{Preparation of $\mathrm{PdCu} / 5 \mathrm{ZA}$ catalyst}

The synthesis and characterization of the $\mathrm{PdCu} / 5 Z \mathrm{~A}_{\mathrm{P}}$ catalyst employed in this work were 
previously described (Jaworski et al., 2014). Briefly, in order to prepare the $\mathrm{Al}_{2} \mathrm{O}_{3}$ support modified with $5 \mathrm{wt} \% \mathrm{ZrO}_{2}, \mathrm{ZrOCl}_{2} \cdot 6 \mathrm{H}_{2} \mathrm{O}$ (Fluka) was added to the $\gamma-\mathrm{Al}_{2} \mathrm{O}_{3}$ support $\left(\gamma-\mathrm{Al}_{2} \mathrm{O}_{3}\right.$ Air Products, surface area $190 \mathrm{~m}^{2} \mathrm{~g}^{-1}$; pore volume $0.50 \mathrm{~m}^{3} \mathrm{~g}^{-1}$ ) suspended in distilled water. $\mathrm{NH}_{4} \mathrm{OH}$ was added drop by drop under constant stirring until a gel formed. This system was aged for 8 days. The solid obtained was washed until no chloride ion was determined by $\mathrm{AgNO}_{3}$ solution, dried at $105^{\circ} \mathrm{C}$ and calcined at $400^{\circ} \mathrm{C}$ for $2 \mathrm{~h}$. The support obtained was called 5ZA. The Pd-based catalyst (1 $\mathrm{wt} \%$ ) was prepared by impregnating the 5ZA support with a solution of $\mathrm{H}_{2} \mathrm{PdCl}_{4}$ prepared from $\mathrm{PdCl}_{2}$ (Sigma-Aldrich) in $\mathrm{HCl}(\mathrm{pH}=1)$. The solid obtained was dried at $105^{\circ} \mathrm{C}$ and calcined in air at $400^{\circ} \mathrm{C}$. After that, this monometallic catalyst was impregnated with a solution of $\mathrm{Cu}\left(\mathrm{NO}_{3}\right)_{2}$ (Merck), so as to obtain $0.3 \mathrm{wt} \% \mathrm{Cu}$ on the support. The bimetallic catalyst was first dried at $105^{\circ} \mathrm{C}$ and then calcined at $400^{\circ} \mathrm{C}$.

\section{Preparation of cordierite monoliths}

The structured support used was ceramic cordierite monoliths (Corning). They were sectioned in a suitable size (length: $3 \mathrm{~cm}$, cross section: $0.785 \mathrm{~cm}^{2}$ ), placed in an ultrasonic water bath to remove possible impurities, dried, weighed and identified. The scheme of the monoliths used is shown in Figure 1.

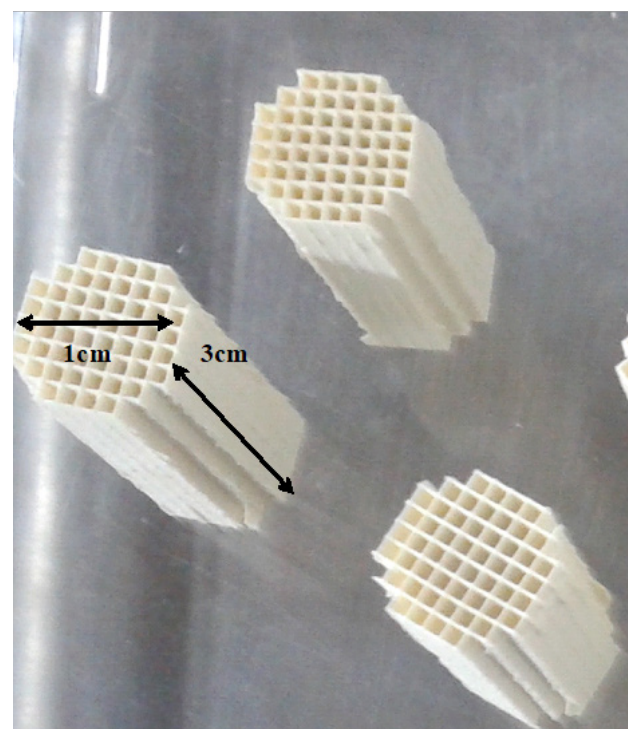

Figure 1. Scheme of the monoliths used.
The catalyst was incorporated into the monolithic structure using the washcoating method. This method consists of immersing the monolith in a suspension of the finely milled catalyst. In order to prepare a stable suspension, it was necessary to determine the zeta potential (pZ) of the $\mathrm{PdCu} / 5 \mathrm{ZA}$ catalyst. For this determination, the $\mathrm{PdCu} / 5 \mathrm{ZA}$ catalyst was milled to a particle size between 120 and 140 mesh. The determination of the $\mathrm{pZ}$ was carried out with solutions of $\mathrm{KCl}, \mathrm{KOH}$ and $\mathrm{HCl}$ using Zeta-Meter System 3.0 equipment.

For the preparation of the $\mathrm{PdCu} / 5 \mathrm{ZA}$ suspension, the catalyst was finely milled for 5 or $10 \mathrm{~h}$ in a planetary ball mill (Fritsch Pulverisette 6). The particle size of the $\mathrm{PdCu} / 5 \mathrm{ZrAl}_{\mathrm{p}}$ catalyst after milling was determined using a Fritsch A-20 photosedimentograph and 2\% Triton X-10 as surfactant.

\section{Preparation of the structured catalysts}

In order to obtain a stable coating of the $\mathrm{PdCu} / 5 \mathrm{ZA} \mathrm{P}_{\mathrm{P}}$ catalyst on the monolith structure, different preparation strategies were evaluated. For example, the effect of the milling time for the $\mathrm{PdCu} / 5 \mathrm{ZA}_{\mathrm{p}}$ catalyst $(5$ or $10 \mathrm{~h}$ ), the catalyst concentration in the suspension (14 or 20 $\mathrm{wt} \%$ ), the stabilizer agent (colloidal alumina $\mathrm{Nyacol}^{\circledR}$ Al 20 or polyvinyl alcohol (PVA)) and the precoating of monoliths with colloidal alumina Nyacol ${ }^{\circledR} \mathrm{Al} 20$ as primer were studied.

To prepare the structured catalyst, an aqueous suspension of the finely milled $\mathrm{PdCu} / 5 \mathrm{ZA}_{\mathrm{p}}$ catalyst was prepared and the $\mathrm{pH}$ was adjusted to 9.5 with a concentrated $\mathrm{NaOH}$ solution. The suspension obtained was placed in an ultrasound device for $30 \mathrm{~min}$ and its stability was observed. The cordierite monoliths were immersed in this suspension for $1 \mathrm{~min}$. The excess suspension was eliminated by centrifugation at 650 rpm for $1 \mathrm{~min}$. Finally, the monoliths containing the deposited catalyst were dried at $105^{\circ} \mathrm{C}$, calcined at $400^{\circ} \mathrm{C}$ for $2 \mathrm{~h}$ and weighed.

The monolithic catalysts prepared are listed in Table 1, where $\mathrm{N}$ or $\mathrm{P}$ indicates the $\mathrm{Nyacol}{ }^{\circledR} \mathrm{Al} 20$ or PVA stabilizer, respectively, 14 or 20 is the weight percentage of the catalyst in the suspension, 5 or 10 indicates the powder catalyst milling time, Pr indicates the precoating with colloidal alumina Nyacol ${ }^{\circledR}$ Al 20 as primer, and (1) or (2) is the number of monolith

Table 1. Nomenclature and methodologies employed to deposit the $\mathrm{PdCu} / 5 \mathrm{ZA}$ p catalyst on monoliths.

\begin{tabular}{cccccc}
\hline Monolith & $\begin{array}{c}\text { Milling } \\
\text { time (h) }\end{array}$ & Pre-coating & Stabilizer & $\begin{array}{c}\text { Suspension } \\
\text { concentration (wt.\%) }\end{array}$ & $\begin{array}{c}\text { Number } \\
\text { of immersions }\end{array}$ \\
\hline N20-5(1) & 5 & No & Nyacol & 20 & 1 \\
N14-5(1) & 5 & No & Nyacol & 14 & 1 \\
N14-5(2) & 5 & No & Nyacol & 14 & 2 \\
N14-10(1) & 10 & No & Nyacol & 14 & 1 \\
N14-10 Pr(1) & 10 & Yes & Nyacol & 14 & 1 \\
P14-10(1) & 10 & No & PVA & 14 & 1 \\
P14-10 $P r(1)$ & 10 & Yes & PVA & 14 & 1 \\
\hline
\end{tabular}


dips in the suspension. Four pieces were prepared for each condition to verify the reproducibility of the preparation method.

\section{Adherence test}

In order to evaluate the coating adherence of the $\mathrm{PdCu} / 5 Z_{\mathrm{p}}$ catalyst on the monoliths, an adaptation of a previously reported method (Barbero, et al., 2008) was used. The structured catalysts were immersed in distilled water inside a sealed beaker and subjected to ultrasonic agitation at approximately $30^{\circ} \mathrm{C}$ for $30 \mathrm{~min}$. Then, the structured catalysts were dried at $105{ }^{\circ} \mathrm{C}$ for $6 \mathrm{~h}$ and calcined at $400^{\circ} \mathrm{C}$ for $2 \mathrm{~h}$. These conditions are identical to that employed during the washcoating of $\mathrm{PdCu} / 5 Z_{\mathrm{p}}$ catalyst. Therefore, the weight difference before and after the ultrasound treatment allows one to determine the coating adherence as following:

Adherence $(\%)=\left[1-\frac{\left(\mathrm{W}_{\mathrm{bu}}-\mathrm{W}_{\mathrm{au}}\right)}{\mathrm{W}_{\mathrm{cat}}}\right] \times 10$

where $\mathrm{W}_{\mathrm{bu}}$ is the weight before ultrasonic treatment, $\mathrm{W}_{\mathrm{au}}$ the weight after ultrasonic treatment, and $\mathrm{W}_{\mathrm{ap}}$ the weight of $\mathrm{PdCu} / 5 \mathrm{ZA} \mathrm{A}_{\mathrm{p}}$ catalyst retained by washcoating.

\section{Characterization of $\mathbf{P d C u} / \mathbf{5 Z A}$ structured catalysts}

Monolithic catalysts were characterized by SEMEDX microscopy. SEM-EDX measurements were carried out using a FEI Quanta 200 scanning electron microscope equipped with an energy dispersive X-ray spectroscopy facility (EDX SDD Apollo 40). In order to draw conclusions about the distribution of the components in the samples, backscattered electron (BSE) images were taken.

The temperature-programmed reduction (TPR) experiments were carried out in a conventional flow system using a reactive gas stream $\left(5 \% \mathrm{H}_{2}\right.$ balanced with Ar) flowing at $25 \mathrm{~mL} \mathrm{~min}^{-1}$ over $50 \mathrm{mg}$ of sample. The temperature was raised from room temperature to $800{ }^{\circ} \mathrm{C}$ at $10{ }^{\circ} \mathrm{C} \mathrm{min}{ }^{-1}$. Hydrogen uptake during the reduction was analysed on-line by a Shimadzu GC-8A gas chromatograph equipped with a thermal conductivity detector (TCD).

The textural properties of the supports were measured by $\mathrm{N}_{2}$ adsorption-desorption at $-196{ }^{\circ} \mathrm{C}$ using a Micromeritics Accusorb 2100E apparatus.

\section{Analysis of the catalytic properties}

A tubular glass reactor (internal diameter: $1.1 \mathrm{~cm}$; length: $3.1 \mathrm{~cm}$ ) containing the structured catalysts (Figure 2) was used to study $\mathrm{NO}_{3}{ }^{-}$removal from water. Fifty $\mathrm{mL}$ of degassed aqueous solution containing $100 \mathrm{ppm}$ of $\mathrm{NO}_{3}^{-}$was loaded into the system and continuously bubbled with $\mathrm{H}_{2}$. The solution was recirculated with a peristaltic pump at a flow rate of 5

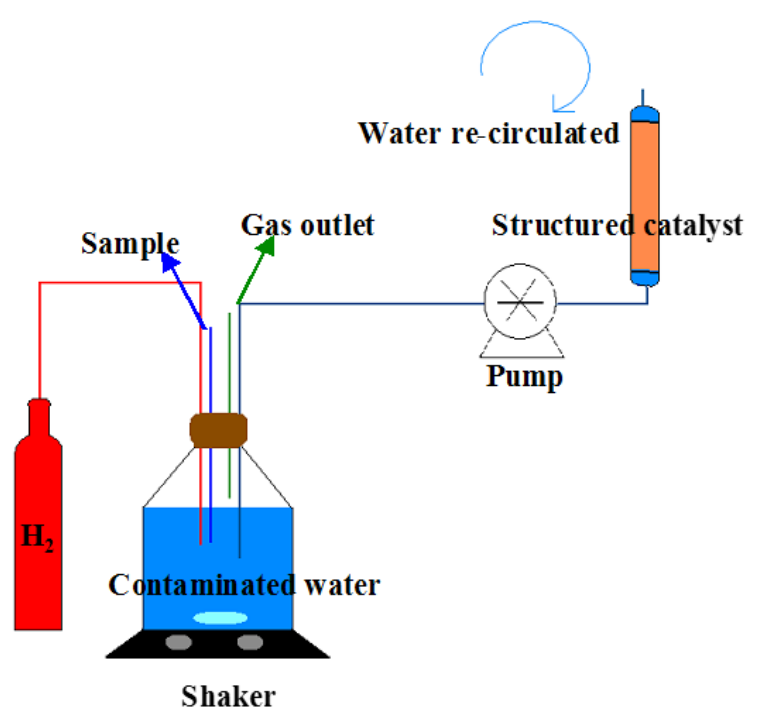

Figure 2. Schematic diagram of the experimental equipment.

$\mathrm{mL} / \mathrm{min}$. The reaction was carried out for $20 \mathrm{~h}$ at room temperature and atmospheric pressure.

Samples were periodically taken to determine $\mathrm{NO}_{3}{ }^{-}$ and $\mathrm{NO}_{2}^{-}$concentration with an ion chromatograph (Metrohm 790 Personal IC). $\mathrm{NH}_{4}^{+}$was determined at the end of the reaction by a colorimetric method using a UV-Vis spectrophotometer (UV-Vis Thermo Spectronic Helios Gamma), following a modified Berthelot method (Marchesini et al., 2010). The conversion values of $\mathrm{NO}_{3}^{-}\left(\mathrm{X}_{\mathrm{NO}_{-}} \%\right)$ as well as selectivities towards $\mathrm{NO}_{2}^{-}\left(\mathrm{S}_{\mathrm{NO2}-} \%\right), \mathrm{NH}_{4}^{+}\left(\mathrm{S}_{\mathrm{NH} 4+} \%\right)$ and $\mathrm{N}_{2}\left(\mathrm{~S}_{\mathrm{N} 2} \%\right)$ after $20 \mathrm{~h}$ of reaction for all the catalysts studied were calculated according to:

$\mathrm{X}_{\mathrm{NO}_{3}^{-}}=\frac{\left[\mathrm{NO}_{3}^{-}\right]_{\text {initial }}-\left[\mathrm{NO}_{3}^{-}\right]_{\mathrm{t}}}{\left[\mathrm{NO}_{3}^{-}\right]_{\text {initial }}} \times 100 \%$

$\mathrm{S}_{\mathrm{NO}_{2}^{-}}=\frac{\left[\mathrm{NO}_{2}^{-}\right]_{\mathrm{t}}}{\left[\mathrm{NO}_{3}^{-}\right]_{\text {initial }}-\left[\mathrm{NO}_{3}^{-}\right]_{\mathrm{t}}} \times 100 \%$

$\mathrm{S}_{\mathrm{NH}_{4}^{+}}=\frac{\left[\mathrm{NH}_{4}^{+}\right]_{\mathrm{t}}}{\left[\mathrm{NO}_{3}^{-}\right]_{\text {initial }}-\left[\mathrm{NO}_{3}^{-}\right]_{\mathrm{t}}} \times 100 \%$

$\mathrm{S}_{\mathrm{N}_{2}}=100-\mathrm{S}_{\mathrm{NO}_{2}^{-}}(\%)-\mathrm{S}_{\mathrm{NH}_{4}^{+}}(\%)$

\section{RESULTS}

\section{Characterization of the structured catalysts}

The uncoated monolith and the structured catalysts were analysed by SEM-EDX microscopy. A representative SEM-EDX analysis of a portion of the 


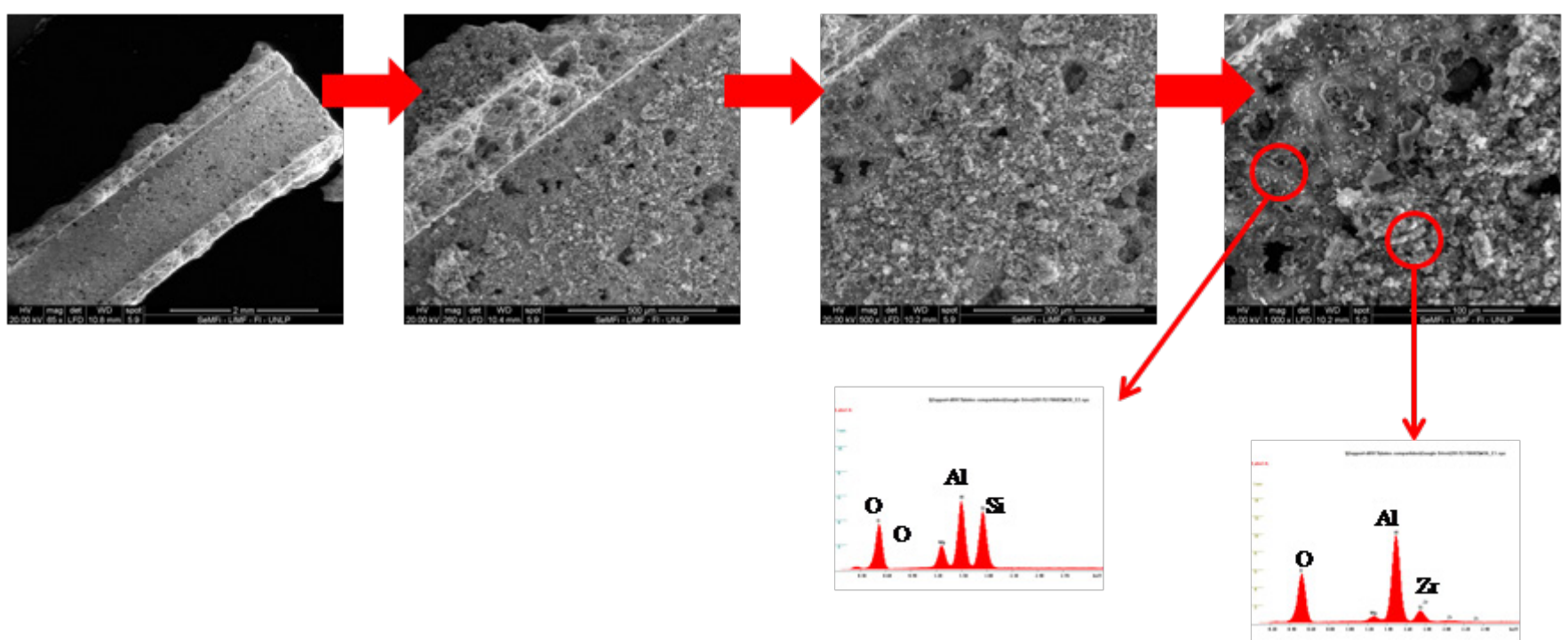

Figure 3. SEM image and EDX analysis for the structured catalyst N14-10(1).

catalyst N14-10(1) is shown in Figure 3. The arrows indicate a progressive increase of zoom for the images. The circles indicate the points where the elements were analysed by EDX.

The areas of the monolith covered with catalyst were clearly distinguished in all the analysed monoliths. The EDX analysis of the uncovered areas showed the presence of $\mathrm{O}, \mathrm{Mg}, \mathrm{Al}$ and $\mathrm{Si}$, representative of cordierite, while the areas with the catalyst presented $\mathrm{O}, \mathrm{Al}$ and $\mathrm{Zr}$, which indicates the effective coating of the $\mathrm{PdCu} / 5 \mathrm{ZA}$ p catalyst on the monolith surface. As expected, it was not possible to differentiate the metals $\mathrm{Pd}$ and $\mathrm{Cu}$ because they are in concentrations below the detection limit of EDX.

To determine if the catalyst particles were modified during the washcoating process, the textural properties (Figure 4) and the TPR profile (Figure 5) of the original $\mathrm{PdCu} / 5 \mathrm{ZA}_{\mathrm{p}}$ catalyst were compared with those of the

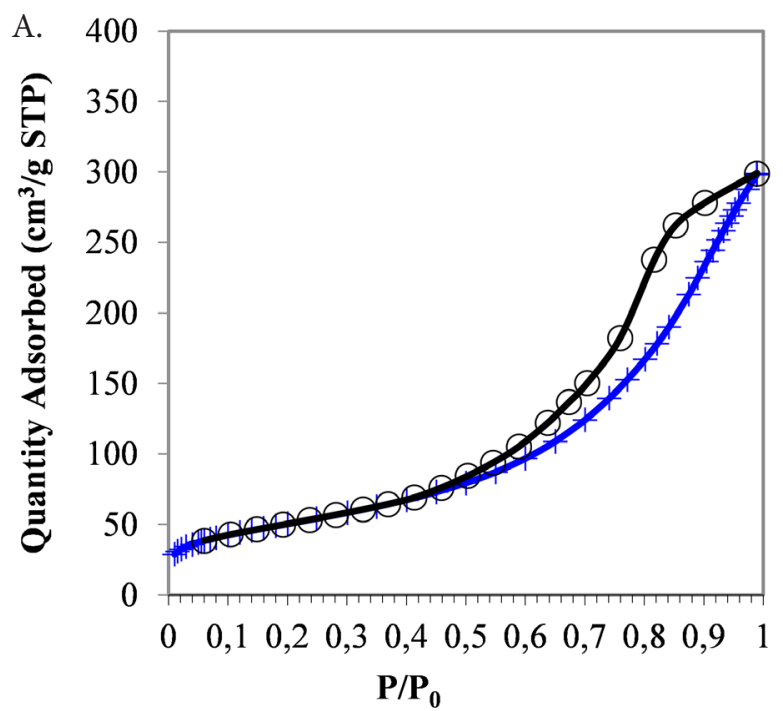

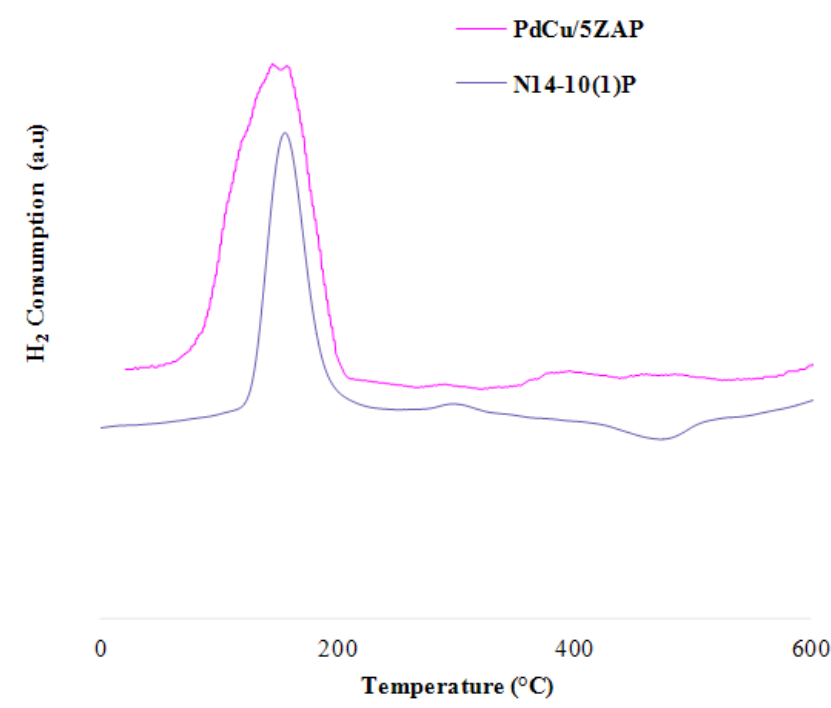

Figure 5. TPR profile of the catalyst $\mathrm{PdCu} / 5 \mathrm{ZA}$ and N14-10(1) $\mathbf{P}^{*}$

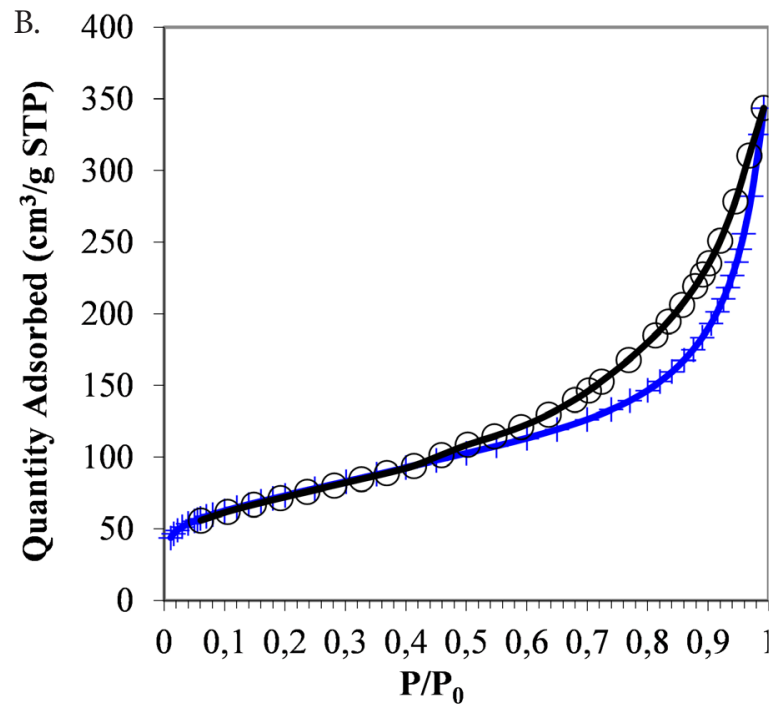

Figure 4. $\mathrm{N}_{2}$ adsorption/desorption isotherms at for a) $\mathrm{PdCu} / 5 \mathrm{ZA}, \mathrm{p}$, b) N14-10(1) $)_{\mathbf{P}}$. 
solid recovered by drying of the suspension used to prepare monolith N14-10(1) (hereinafter called N14$\left.10(1)_{\mathrm{p}}\right)$.

The $\mathrm{N}_{2}$ adsorption/desorption isotherms for the powder catalyst $\mathrm{PdCu} / 5 \mathrm{ZA}_{\mathrm{P}}$ and $\mathrm{N} 14-10(1)_{\mathrm{P}}$ are shown in Figure 4 a) and b), respectively. The catalytic materials analysed have similar isotherms corresponding to a type IV isotherm according to the IUPAC classification, characteristic of mesoporous solids (Muttakin et al., 2018).

The TPR profile for the catalyst $\mathrm{PdCu} / 5 \mathrm{ZA}$ p was described in a previous paper (Jaworski, et al., 2014) and was similar for the solid N14-10(1) $)_{\mathbf{P}}$, Figure 5. In both profiles it is possible to distinguish two different peaks: a main peak centred around $150^{\circ} \mathrm{C}$ and a small peak which extends between 300 and $400^{\circ} \mathrm{C}$. The first peak is assigned to the reduction of $\mathrm{PdO}$ to $\mathrm{Pd}^{0}$, and the reduction of copper oxides promoted by the presence of the noble metal Pd (Resende et al., 2018, Zhuang, et al., 2010). The Pd crystals favor the spillover of $\mathrm{H}_{2}$ that causes the $\mathrm{Cu}$ oxides to be reduced at lower temperature when compared to a monometallic $\mathrm{Cu}$ catalyst $\left(300-400^{\circ} \mathrm{C}\right)$ (Lei et al. 2018; Yuan et al., 2017). The second peak corresponds to the reduction of $\mathrm{CuO}$ to $\mathrm{Cu}^{\circ}$ (Lei et al., 2018).

The similarity of the TPR profiles for the catalysts $\mathrm{PdCu} / 5 Z_{\mathrm{P}}$ and $\mathrm{N} 14-10(1)_{\mathrm{P}}$ show that the $\mathrm{Pd}-\mathrm{Cu}$ interaction is not modified when the catalyst is finely milled and used for preparing the suspension.

\section{Determination of the isoelectric point}

As previously mentioned, it was necessary to determine the $\mathrm{pZ}$ of the $\mathrm{PdCu} / 5 \mathrm{ZA}$ p catalyst prior to preparing the suspensions. In Figure 6 it can be seen that the isoelectric point for the $\mathrm{PdCu} / 5 \mathrm{ZA}$ catalyst was approximately 4.5. Then, the $\mathrm{pH}$ selected to prepare the $\mathrm{PdCu} / 5 \mathrm{ZA}$ p catalyst suspension was 9.5 , which is far enough away from pZ. In this way, the agglomeration of particles was avoided.

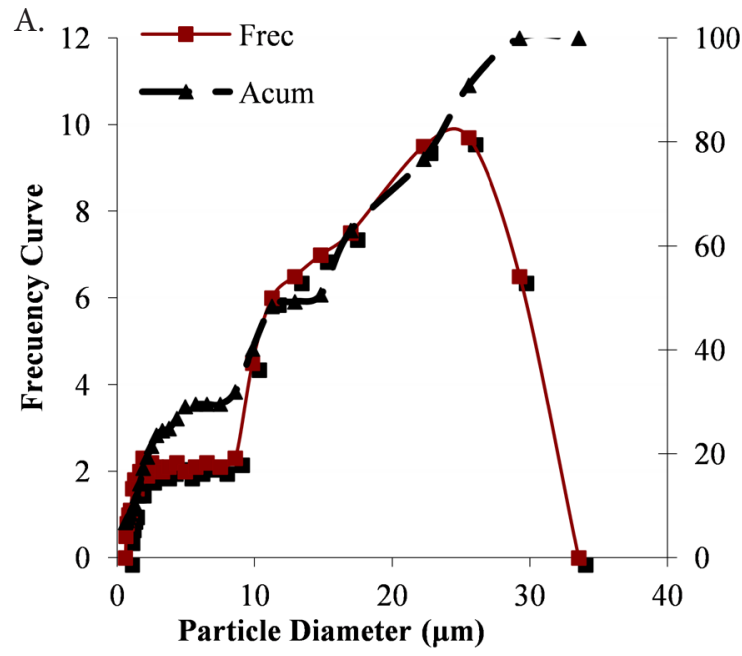

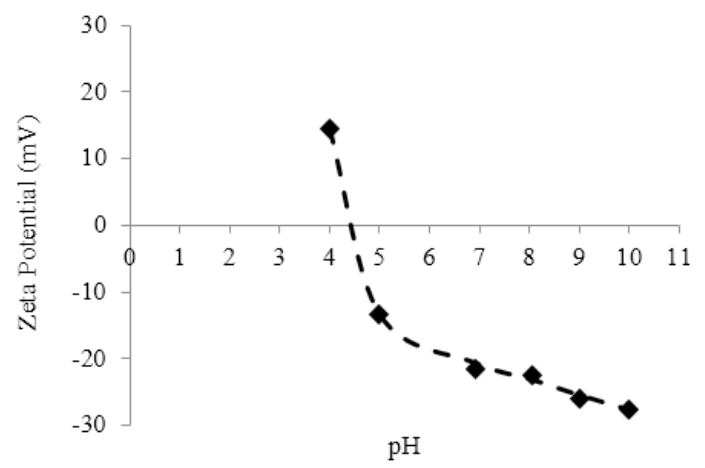

Figure 6. Zeta potential as a function of $\mathrm{pH}$ for the $\mathrm{PdCu} / 5 \mathrm{ZA}_{\mathrm{p}}$ catalyst.

\section{Determination of particle size}

Figure 7 shows the curves corresponding to the determination of the particle size distribution after the milling process $(5 \mathrm{~h}$ and $10 \mathrm{~h})$.

The continuous line with square symbols represents the particle size distribution, while the dashed line with triangle symbols represents the accumulative distribution. From these curves it is possible to read the $\mathrm{d}_{50}$ or $\mathrm{d}_{90}(50 \%$ or $90 \%$ of the particles of the suspension are smaller than that value, respectively). For the milling time of $5 \mathrm{~h}, \mathrm{~d}_{90}$ of $25.5 \mu \mathrm{m}$ was obtained. For the $10 \mathrm{~h}$ milling time, the $\mathrm{d}_{50}$ was $7 \mu \mathrm{m}$ and the $\mathrm{d}_{90}$ $13.5 \mu \mathrm{m}$ approximately. Evidently, the particle sizes for $5 \mathrm{~h}$ milling time are larger than for $10 \mathrm{~h}$ milling time.

\section{Results of coated monoliths}

Table 2 presents the catalyst mass gained by washcoating and the coating adherence for all prepared monoliths. The second column shows the weight increase observed after washcoating of the cordierite monolith, which correspond to the content of $\mathrm{PdCu} / 5 \mathrm{ZA} \mathrm{P}_{\mathrm{P}}$ catalyst on the cordierite support expressed as weight percentage. The values reported are an average of the four pieces prepared. The third column shows the percentage of $\mathrm{PdCu} / 5 \mathrm{ZA}$ catalyst

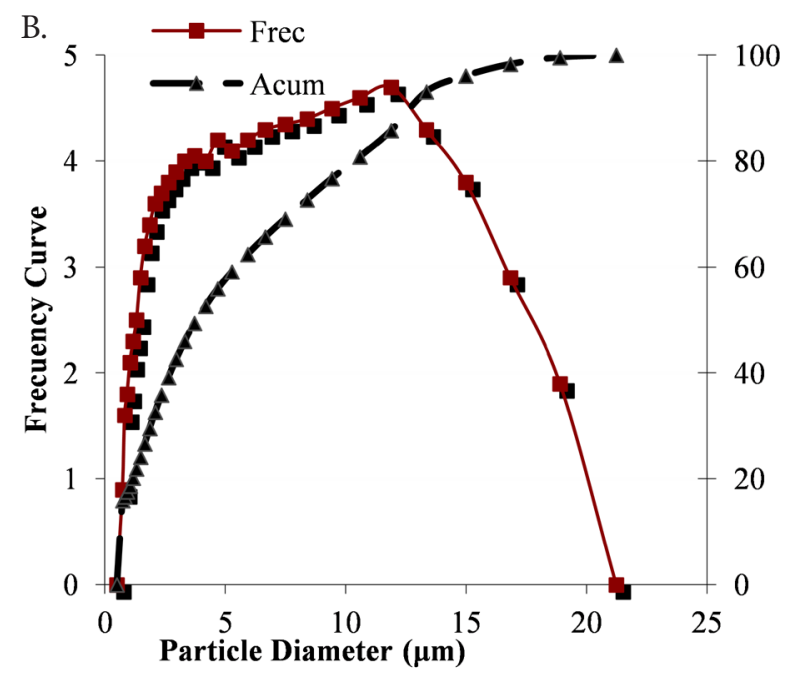

Figure 7. Determination of the particle size after the milling process. Left, $5 \mathrm{~h}$ milling. Right, $10 \mathrm{~h}$ milling. 
Table 2. Weight percentage of $\mathrm{PdCu} / 5 \mathrm{ZA}$ p catalysts retained after the washcoating (second column), coating adherence (third column) and net content of $\mathrm{PdCu} / 5 Z_{\mathrm{p}}$ catalyst after the adherence test (fourth column).

\begin{tabular}{cccc}
\hline Monolith & $\begin{array}{c}\text { Weight } \\
\text { increase } \\
(\mathbf{w t} \%)\end{array}$ & $\begin{array}{c}\text { Adherence } \\
(\mathbf{\%})\end{array}$ & $\begin{array}{c}\text { Catalyst } \\
\text { net content } \\
\text { (wt\%) }\end{array}$ \\
\hline $\mathrm{N} 20-5(1)$ & $4.79 \pm 0.03$ & 48.57 & 2.33 \\
$\mathrm{~N} 14-5(1)$ & $4.35 \pm 0.02$ & 66.67 & 2.90 \\
$\mathrm{~N} 14-5(2)$ & $8.45 \pm 0.01$ & 40.00 & 3.38 \\
$\mathrm{~N} 14-10(1)$ & $3.33 \pm 0.02$ & 90.00 & 3.00 \\
$\mathrm{~N} 14-10 \operatorname{Pr}(1)$ & $4.55 \pm 0.02$ & 61.67 & 2.80 \\
P14-10(1) & $2.05 \pm 0.01$ & 83.33 & 1.71 \\
$\mathrm{P} 14-10 \operatorname{Pr}(1)$ & $2.88 \pm 0.02$ & 75.00 & 2.16 \\
\hline
\end{tabular}

retained after the adherence test with respect to the catalyst retained by the washcoating process. The net content of catalyst after the adherence test is shown in the last column. These results are discussed below.

\section{Effect of suspension concentration}

The structured catalyst prepared using the $20 \mathrm{wt} \%$ suspension (N20-5(1)) showed a non-uniform coverage and channels blocked by the active phase.

To avoid these problems and to obtain a homogeneous layer of the catalyst on the monolith, a more dilute suspension, $14 \mathrm{wt} \%$, was used (monolith N14-5(1)). The monoliths were coated with this suspension and Table 2 (second column) shows that the mass gain of catalyst is smaller for N20-5(1) than for N14-5(1) monolith. A better adherence (third column) is achieved when the $14 \mathrm{wt} \%$ suspension in used. In this way, higher catalyst net content is obtained after the adherence test (fourth column).

\section{Effect of the number of immersions}

To increase the amount of catalyst in the monoliths, two immersions were made with the $14 \mathrm{wt} \%$ suspension, obtaining N14-5(2) monolith. From Table 2 it is noted that, with two immersions, about the double of catalyst was retained on the monolith (second column). However, a significant amount of catalyst was not retained after the adherence test for this monolith. As was previously reported, it is possible that, with a greater number of immersions, an unstable coating will be formed on the monolith (Bosko et al., 2014). The attraction forces between the first and the second layers deposited on the monolith are weak. Therefore, the coating adherence decreases for subsequent immersions.

\section{Effect of catalyst particle size}

In order to analyse the effect of the catalyst particle size, the $\mathrm{PdCu} / \mathrm{ZA}_{\mathrm{p}}$ catalyst was milled for 5 or $10 \mathrm{~h}$ (Figure 7) and two monoliths were prepared (monolith N14-5(1) and N14-10(1)). In Table 2, it can be seen that the milling time affected the final adherence of the catalyst. The monolith coated with the powder milled for $10 \mathrm{~h}$ was more stable than that coated with the powder milled for $5 \mathrm{~h}$. This implies that the small particle size favours the adherence of the coating.

\section{Effect of the stabilizer agent}

Alternatively to the use of colloidal alumina Nyacol ${ }^{\circledR} \mathrm{Al} 20$ as the stabilizer agent of the suspension, PVA was used and the monolith P14-10(1) was prepared. In comparison with the monolith N14-10(1), the monolith prepared with PVA retained less catalyst amount and presented lower coating adherence (Table 2).

\section{Effect of the use of a primer}

The adherence of the catalyst to the monolith is a crucial factor. For this reason, to improve adherence, usually the monolith is firstly covered with a layer of alumina or silica oxides. The function of these oxides is to provide a bond between the catalyst particles and the monolith, without affecting the catalytic performance (Yuan et al., 2016). In this work, the cordierite monoliths were immersed in a suspension of colloidal alumina Nyacol ${ }^{\circledR}$ Al2 20 for 1 min. The excess of the suspension was removed by centrifugation at 650 rpm for $1 \mathrm{~min}$. The monoliths containing the primer were dried, calcined at $500{ }^{\circ} \mathrm{C}$ for $2 \mathrm{~h}$ and weighed. The $\mathrm{PdCu} / 5 \mathrm{ZA} \mathrm{p}_{\mathrm{p}}$ powder catalyst (14 $\mathrm{wt} \%$ suspension) milled for $10 \mathrm{~h}$ was then deposited on these monoliths. Two suspensions were made using the stabilizers previously evaluated, colloidal alumina or PVA, and the monoliths obtained were N14-10 Pr(1) and P14-10 $\operatorname{Pr}(1)$.

By comparing the monoliths without primer (N1410(1) and P14-10(1)) with the monoliths with primer (N14-10 $\operatorname{Pr}(1)$ and $\mathrm{P} 14-10 \operatorname{Pr}(1))$, it can be seen that the use of a primer was not favourable (Table 2). The amount of catalyst retained was higher compared to the same monoliths containing no primer (Table 2, second column) but the adherence of these coatings was lower (Table 2, third column). It was suggested that the presence of a primer could cause the loss of the surface roughness of the monolithic support and, for that reason, the adherence decreases (Yuan et al., 2016).

\section{Catalytic reaction}

Before testing the monolithic catalysts in the $\mathrm{NO}_{3}{ }^{-}$ removal reaction in water, blank tests were performed. The first one consisted of the use of $50 \mathrm{~mL}$ of a 100 ppm $\mathrm{NO}_{3}{ }^{-}$solution in the presence of $\mathrm{H}_{2}$ bubbling but in the absence of catalyst. The second one consisted in the use of the structured support covered by powder $\mathrm{Al}_{2} \mathrm{O}_{3}$ or 5ZA supports in the presence of $100 \mathrm{ppm}$ of $\mathrm{NO}_{3}{ }^{-}$and $\mathrm{H}_{2}$. In both cases, it was found that $\mathrm{NO}_{3}{ }^{-}$ removal was null. 
All $\mathrm{PdCu} / 5 \mathrm{ZA}$ monolithic catalysts were evaluated in the $\mathrm{NO}_{3}{ }^{-}$removal reaction. The $\mathrm{PdCu} / 5 \mathrm{ZA}$ p powder catalyst was included as a reference. The results are shown in Table 3.

This study showed that the structured catalysts prepared were active in the removal of $\mathrm{NO}_{3}^{-}$. A maximum conversion of $83 \%$ after $20 \mathrm{~h}$ of reaction was found for the monolith N14-10(1). This monolith also had the best $\mathrm{N}_{2}$ selectivity and the highest nitrate specific conversion (calculated as (nitrate conversion)/ (catalyst mass) ratio, Table 3 , eighth column). For all the monoliths studied, the selectivity to $\mathrm{N}_{2}$ was higher than $96 \%$, except for the monolith N20-5(1). These results make these systems promising candidates to be used as catalysts for $\mathrm{NO}_{3}^{-}$removal from water, although some operation conditions could still be improved.

In order to evaluate the existence of diffusional effects on $\mathrm{NO}_{3}{ }^{-}$removal, another test was carried out using an aliquot of the $\mathrm{PdCu} / 5 \mathrm{ZA}$ powder catalyst obtained from the suspension used to prepare the catalyst N14-10(1). The reaction was carried out in a semibatch system using $45 \mathrm{mg}$ of this powder, which is equal to the catalyst mass retained on the monolith N14-10(1). The reaction conditions were the same as in the previous tests. The final concentrations detected for $\mathrm{NO}_{3}^{-}, \mathrm{NO}_{2}^{-}$and $\mathrm{NH}_{4}^{+}$were 0 ppm, $0.5 \mathrm{ppm}$ and $0.3 \mathrm{ppm}$, respectively. The difference in activity between the powder and the monolith N14-10(1) could be assigned to diffusion problems of the reactants and/ or products in the structured system.

In summary, from the results shown in Tables 2 and 3, the preparation of structured catalysts using the catalyst $\mathrm{PdCu} / 5 \mathrm{ZA}$ milled for $10 \mathrm{~h}$ in the absence of a primer is favourable since the best results in terms of catalyst retention and catalytic activity were obtained using the N14-10(1) monolith.

As previously mentioned, in the blank tests using the cordierite monolith covered with the supports $\mathrm{Al}_{2} \mathrm{O}_{3}$ or $5 \mathrm{ZA}, \mathrm{NO}_{3}^{-}$removal was null. Since the support itself is not active, the $\mathrm{NO}_{3}^{-}$removal is attributed to the $\mathrm{PdCu}$ active phase. In this sense, the same reaction mechanism described by Jaworski et al. (2014) in a previous work is postulated. In this mechanism, the $\mathrm{NO}_{3}$ - ions are adsorbed on the oxygen vacancy sites
(Lewis acid sites) generated by the presence of $\mathrm{ZrO}_{2}$ in the support.

In order to evaluate the potential reuse of the monolith N14-10(1), after reaction, the monolith was washed with distilled water, dried, calcined at $400^{\circ} \mathrm{C}$ for $1 \mathrm{~h}$ and reduced at $400^{\circ} \mathrm{C}$ for $1 \mathrm{~h}$. The reaction was carried out using the original $\mathrm{NO}_{3}^{-}$solution (100 ppm of $\mathrm{NO}_{3}^{-}$). This process was repeated for each cycle. The results obtained are listed in Table 4.

The results from Table 4 show that there is a certain deactivation in the removal of $\mathrm{NO}_{3}^{-}$after each reuse, while the selectivity to $\mathrm{NO}_{2}^{-}$and $\mathrm{NH}_{4}^{+}$is maintained. The mass of the catalyst remains constant before and after each use. Thus, the decrease in activity for $\mathrm{NO}_{3}^{-}$ removal could be assigned to the loss of some of the active sites.

For these catalysts to have a practical application, it is necessary to evaluate them in water intended for human consumption. In this sense, the monolith with the best catalytic performance, N14-10(1), was evaluated using water samples taken from the Puelche Aquifer. Two samples of groundwater from this aquifer were extracted and analysed, and were designated $\mathrm{C}$ and $\mathrm{P}$, as shown in Table 5. The nitrate content of these samples was higher than that allowed by current regulations. The Puelche Aquifer is one of the most exploited water reservoirs in Argentina, since it supplies drinking water to the Buenos Aires Metropolitan Region (Greater Buenos Aires), one of the most densely populated areas of Argentina. The Puelche Aquifer has low salinity (approximately $585 \mathrm{mg} / \mathrm{L}$ ), being of the sodium bicarbonate type. Its potability is only affected by the $\mathrm{NO}_{3}^{-}$content, especially in urbanized areas (Armengol et al., 2017; Zabala et al. 2016).

Table 4. Conversion of $\mathrm{NO}_{3}^{-}$and concentration of $\mathrm{NO}_{2}^{-}$and $\mathrm{NH}_{4}^{+}$after re-use of the N14-10(1) monolith.

\begin{tabular}{|c|c|c|c|c|c|c|}
\hline Cycle & $\mathrm{X}_{\mathrm{NO}-} \%$ & $\begin{array}{l}\text { ppm } \\
\text { NO }_{2}^{-}\end{array}$ & $\begin{array}{l}\text { ppm } \\
\text { NH }_{4}{ }^{+} \\
\end{array}$ & $\begin{array}{c}\mathbf{S}_{\mathrm{NO2}-} \\
(\%)\end{array}$ & $\begin{array}{c}\mathbf{S}_{\mathrm{NH} 4+} \\
(\%)\end{array}$ & $\begin{array}{l}\mathrm{S}_{\mathrm{N} 2} \\
(\%)\end{array}$ \\
\hline $1^{\circ}$ & 83 & 0.4 & 0.55 & 0.48 & 0.66 & 98.86 \\
\hline $2^{\circ}$ & 75 & 0.9 & 0.3 & 1.20 & 0.40 & 98.40 \\
\hline $3^{\circ}$ & 68 & 0.75 & 0.3 & 1.10 & 0.44 & 98.46 \\
\hline $4^{\circ}$ & 61 & 0.4 & 0.25 & 0.66 & 0.41 & 98.93 \\
\hline
\end{tabular}

Table 3. Conversion of $\mathrm{NO}_{3}^{-}$and concentration of $\mathrm{NO}_{2}^{-}$and $\mathrm{NH}_{4}^{+}$for the monoliths prepared after 20 hours of reaction.

\begin{tabular}{|c|c|c|c|c|c|c|c|}
\hline Monolith & $\begin{array}{c}\mathrm{X}_{\mathrm{NO3}-} \\
(\%)\end{array}$ & $\begin{array}{l}\text { ppm } \\
\mathrm{NO}_{2}^{-}\end{array}$ & $\begin{array}{c}\text { ppm } \\
\mathbf{N H}_{4}{ }^{+}\end{array}$ & $\begin{array}{c}\mathrm{S}_{\mathrm{NO2-}} \\
(\%)\end{array}$ & $\begin{array}{c}\mathrm{S}_{\mathrm{NH} 4+} \\
(\%)\end{array}$ & $\begin{array}{l}\mathrm{S}_{\mathrm{N} 2} \\
(\%)\end{array}$ & $\begin{array}{l}\mathbf{X}_{\text {NO3- }} \\
/ \mathbf{g}_{\text {cat }} *\end{array}$ \\
\hline $\mathrm{N} 20-5(1)$ & 45 & 0.8 & 2 & 1.78 & 4.44 & 93.78 & 13.24 \\
\hline N14-5(1) & 75 & 0.55 & 0.4 & 0.73 & 0.53 & 98.73 & 18.75 \\
\hline N14-5(2) & 78 & 0.75 & 0.6 & 0.96 & 0.77 & 98.27 & 16.25 \\
\hline N14-10(1) & 83 & 0.4 & 0.55 & 0.48 & 0.66 & 98.86 & 18.44 \\
\hline N14-10 $\operatorname{Pr}(1)$ & 61 & 1.2 & 0.7 & 1.97 & 1.15 & 96.89 & 16.49 \\
\hline P14-10(1) & 42 & 1.1 & 0.4 & 2.62 & 0.95 & 96.43 & 16.80 \\
\hline P14-10 Pr(1) & 53 & 0.9 & 0.6 & 1.70 & 1.13 & 97.17 & 18.93 \\
\hline $\mathrm{PdCu} / 5 \mathrm{ZA}$ poder & 100 & 0.5 & 0.3 & 0.50 & 0.30 & 99.20 & 20.00 \\
\hline
\end{tabular}

* Nitrate specific conversion calculated as nitrate conversion per catalyst gram. 
Table 5. Elimination of $\mathrm{NO}_{3}^{-}$from water for human consumption after $20 \mathrm{~h}$ of reaction using N14-10(1) monolith*.

\begin{tabular}{|c|c|c|c|c|c|c|c|}
\hline Sample & $\mathrm{ppm}_{\mathrm{i}}{ }^{\left({ }^{1)}\right.} \mathrm{NO}_{3}^{-}$ & $X_{\mathrm{NO3}-} \%$ & $\mathrm{ppm}_{\mathrm{f}}^{\left({ }^{(2)}\right.} \mathrm{NO}_{2}^{-}$ & $\mathrm{ppm}_{\mathrm{f}}^{(2)} \mathrm{NH}_{4}{ }^{+}$ & $\mathrm{S}_{\mathrm{NO2}-(\%)}$ & $\mathrm{S}_{\mathrm{NH} 4+}(\%)$ & $\underline{\mathrm{S}_{\mathrm{N} 2} \%}$ \\
\hline $\mathrm{C}$ & 63 & 49 & 3.3 & 0.8 & 10.64 & 2.58 & 86.78 \\
\hline $\mathrm{P}$ & 58 & 48 & 2.9 & 0.65 & 10.71 & 2.32 & 86.97 \\
\hline
\end{tabular}

* For experimental conditions, see the text. (1) ppm: initial concentration (mg/L). (2) ppm: final concentration (mg/L).

The denitrification reaction was carried out for 20 h using the N14-10(1) monolith and $\mathrm{H}_{2}$ as reducing agent, following the same procedure described in the experimental section for the synthetic samples. The results obtained are presented in Table 5.

The evaluated N14-10(1) monolith was active in the removal of $\mathrm{NO}_{3}^{-}$from real water samples, although a high production of $\mathrm{NO}_{2}^{-}$and $\mathrm{NH}_{4}^{+}$was observed, compared to the results obtained when analysing synthetic samples (Table 3 ). It is suggested that the decrease in the activity and the selectivity towards $\mathrm{N}_{2}$ is due to the masking of the active phase caused by the rest of the ions present in the real water samples, especially to the abundant presence of bicarbonate ions present in the Puelche Aquifer. It is well-established that bicarbonate ions present similar chemical properties to nitrate ions, and thus it can be expected that both anions would be adsorbed on the same catalytic sites. Therefore, the catalytic surface available for nitrate ions will be lower, and so will be the activity (Mendow et al., 2017).

\section{CONCLUSIONS}

Unsupported catalysts are used in numerous industrial processes; however, most of the catalysts used in environmental processes must be supported. In this work structured catalysts were satisfactorily prepared and evaluated in the $\mathrm{NO}_{3}{ }^{-}$removal reaction in water in the presence of $\mathrm{H}_{2}$ as a reducing agent. The powder catalyst $\mathrm{PdCu} / 5 \mathrm{ZA}_{\mathrm{p}}$ was deposited on cordierite monoliths by washcoating. The influence of different variables in the preparation of the structured catalysts was analysed: suspension concentration, particle size, number of immersions, nature of the stabilizer and the use of primer. It was found that the use of a $14 \mathrm{wt} \%$ catalyst suspension is more favourable than a higher suspension concentration $(20 \mathrm{wt} \%)$ in order to prevent blocking of the monolith channels. A milling time of $10 \mathrm{~h}$ (reduction of the particle size of the powder catalyst) improved the amount of catalyst deposited and the adherence of the coating.

The use of colloidal alumina Nyacol as the stabilizer agent was more favourable than the use of PVA to improve the adherence of the catalyst to the monolith. One second immersion increased the retained catalyst mass, but the adherence was low.

The monolith N14-10(1) showed the best catalytic performance among all structured catalysts tested. Though there would be diffusional limitations in the catalytic coating, it should be noted that the selectivity to nitrogen was higher than $97 \%$ and this value remained after the reuse of the catalyst, making it a very promising catalytic system.

This structured catalyst eliminated $50 \%$ of the $\mathrm{NO}_{3}^{-}$ present in samples of water for human consumption, but high $\mathrm{NO}_{2}^{-}$and $\mathrm{NH}_{4}^{+}$generation was detected. Probably the ions present in real water masked the $\mathrm{NO}_{3}{ }^{-}$adsorption sites.

\section{ACKNOWLEDGEMENTS}

We are grateful to Ms Mariela Theiller for her contribution and technical support. The authors would like to thank the following institutions for funding this work: CONICET (PIP 0276 and 1178), UNLP (Project X633 and X700, Subsidio Jóvenes Investigadores, Subsidio de Viajes) and ANCYT (PICT 2016/1391).

\section{REFERENCES}

Armengol, S., Manzano, M., Bea, S., Martínez, S. Identifying and quantifying geochemical and mixing processes in the Matanza-Riachuelo Aquifer System, Argentina. Science of the Total Environment, 599-600, 1417-1432 (2017). https:// doi.org/10.1016/j.scitotenv.2017.05.046

Ashraf, A., Sanz, O., Montes, M., Specchia, S. Insights into the effect of catalyst loading on methane steam reforming and controlling regime for metallic catalytic monoliths. International Journal Of Hidrogen Energy, 43, 11778-11792 (2018). https:// doi.org/10.1016/j.ijhydene.2018.04.126

Barbero, B. P., Costa-Almeida, L., Sanz, O., Morales, M. R., Cadus, L. E., Montes, M. Washcoating of metallic monoliths with a $\mathrm{MnCu}$ catalyst for catalytic combustion of volatile organic compounds. Chemical Engineering Journal, 139, 430-435 (2008). https://doi.org/10.1016/j.cej.2007.12.033

Colman-Lerner, E., Peluso, M., Sambeth, J., Thomas, H. Cerium, manganese and cerium/manganese ceramic monolithic catalysts. Study of VOCs and PM removal. Journal of Rare Earths, 34, 675-682 (2016). https://doi.org/10.1016/S10020721(16)60078-9

Ding, Y., Sun, W., Yang, W., Li, Q. Formic acid as the in-situ hydrogen source for catalytic reduction of nitrate in water by PdAg alloy nanoparticles supported on amine functionalized $\mathrm{SiO}_{2}$. Applied Catalysis B: Environmental, 203, 372-380 (2017). https://doi.org/10.1016/j.apcatb.2016.10.048 
Durkin, D., Ye, T., Choi, J., Livi, K., De Long, H., Trulove, P., Fairbrother, D., Haverhals, L., Shuai, D. Sustainable and scalable natural fiber welded palladium indium catalysts for nitrate reduction. Applied Catalysis B: Environmental, 221, 290-301 (2018). https://doi.org/10.1016/j. apcatb.2017.09.029

Faridullah, Malik, N., Fareed, I., Irshad, M. Reducing the leachability of nitrate phosphorous and heavy metals from soil using waste material. Brazilian Journal of Chemical Engineering, 34), 715-726 (2017). https://doi.org/10.1590/01046632.20170343s20150617

Hamid, S., Bae, S., Lee, W. Novel bimetallic catalyst supported by red mud for enhanced nitrate reduction. Chemical Engineering Journal, 348, 877-887 (2018). https://doi.org/10.1016/j.cej.2018.05.016

Huo, X., van Hoomissen, D. J., Liu, J., Vyas, S., Strathmanna, T. J. Hydrogenation of aqueous nitrate and nitrite with ruthenium catalysts. Applied Catalysis B: Environmental, 211, 188-198 (2017). https://doi.org/10.1016/j.apcatb.2017.04.045

Jaworski, M. A., Lick, I. D., Siri, G. J., Casella, M. L. $\mathrm{ZrO}_{2}$-modified $\mathrm{Al}_{2} \mathrm{O}_{3}$-supported $\mathrm{PdCu}$ catalysts for the water denitrification reaction. Applied Catalysis B: Environmental, 156-157, 53-61 (2014). https:// doi.org/10.1016/j.apcatb.2014.02.048

Jaworski, M., Bertolini, G., Cabello, C., Siri, G., Casella, M. Use of Rh (III)-heteropolymolybdate as potential catalysts for the removal of nitrates in human drinking water: synthesis, characterisation and catalytic performance. Water, Air, \& Soil Pollution, 229, 309-315 (2016). https://doi. org/10.1007/s11270-018-3962-3

Kim, Y.-N., Kim, M. Y., Choi, M. Synergistic integration of catalysis and ion-exchange for highly selective reduction of nitrate into $\mathrm{N}_{2}$. Chemical Engineering Journal, 289, 423-432 (2016). https:// doi.org/10.1016/j.cej.2016.01.002

Labhsetwar, N., Doggali, P., Rayalu, S., Yadad, R., Mistuhashi, T., Haneda, H. Ceramics in Environmental Catalysis: Applications and Possibilities. Chinese Journal of Catalysis, 33, 1611-1621 (2012). https://doi.org/10.1016/S18722067(11)60440-3

Landi, G., Barbato, P. S., Di Benedetto, A., Lisi, L. Optimization of the preparation method of $\mathrm{CuO} / \mathrm{CeO}_{2}$ structured catalytic monolith for $\mathrm{CO}$ preferential oxidation in $\mathrm{H}_{2}$-rich streams. Applied Catalysis B: Environmental, 181, $727-737$ (2016). https://doi.org/10.1016/j.apcatb.2015.08.040

Lei, Y., Luo, Y., Li, X., Lu, J., Mei, Z., Peng, W., Chen, R., Chen, K., Chen, D., He D. The role of samarium on $\mathrm{Cu} / \mathrm{Al}_{2} \mathrm{O}_{3}$ catalyst in the methanol steam reforming for hydrogen production. Catalysis Today, 307, 162-168 (2018). https://doi. org/10.1016/j.cattod.2017.05.072
Li, R., Feng, C., Xi, B., Chen, N., Jiang, Y., Zhao, Y., Li, M., Dang, Q., Zhao, B. Nitrate removal efficiency of a mixotrophic denitrification wall for nitrate-polluted groundwater in situ remediation. Ecological Engineering, 106, 523-531 (2017). https://doi.org/10.1016/j.ecoleng.2017.06.010

Li, K., Jiao, Y., Yang, Z., Zhang, J. Comparative study of $\mathrm{Ni} / \mathrm{Al}_{2} \mathrm{O}_{3}-\mathrm{SiC}$ foam catalysts and powdercatalysts for the liquid-phase hydrogenation of benzaldehyde. Journal of Materials Science \& Technology, 35, 159-167 (2019). https://doi. org/10.1016/j.jmst.2018.09.018

Marchesini, F. A., Gutierrez, L. B., Querini, C. A., Miró, E. E. Pt,In and Pd,In catalysts for the hydrogenation of nitrates and nitrites in water. FTIR characterization and reaction studies. Chemical Engineering Journal, 159, 203-211 (2010). https:// doi.org/10.1016/j.cej.2010.02.056

Martínez, J., Ortiz, A., Ortiz, I. State-of-the-art and perspectives of the catalytic and electrocatalytic reduction of aqueous nitrates. Applied Catalysis B: Environmental, 207, 42-59 (2017). https://doi. org/10.1016/j.apcatb.2017.02.016

Mendow, G., Sánchez, A., Grosso, C., Querini, C. A novel process for nitrate reduction in water using bimetallic $\mathrm{Pd}-\mathrm{Cu}$ catalysts supported on ion exchange resin. Journal of Environmental Chemical Engineering, 5, 1404-1414 (2017). https://doi. org/10.1016/j.jece.2017.01.033

Mirabi, M., Ghaderi, E., Sadabad, H. R. Nitrate reduction using hybrid system consisting of zero valent magnesium powder/activated carbon $\left(\mathrm{Mg}^{0} /\right.$ AC) from water. Process Safety and Environmental Protection, 111, 627-634 (2017). https://doi. org/10.1016/j.psep.2017.08.035

Muñoz-Murillo, A., Martínez, L., Domínguez, M., Odriozola, J., Centeno, M., Selective $\mathrm{CO}$ methanation with structured $\mathrm{RuO} / \mathrm{Al}_{2} \mathrm{O}_{3}$ catalysts. Applied Catalysis B: Environmental 236, 420-427 (2018). https://doi.org/10.1016/j. apcatb.2018.05.020

Muttakin, M., Mitra, S., Thu, K., Ito, K., Bidyut Saha, B. Theoretical framework to evaluate minimum desorption temperature for IUPAC classified adsorption isotherms. International Journal of Heat and Mass Transfer, 122, 795-805 (2018). https:// doi.org/10.1016/j.ijheatmasstransfer.2018.01.107

Özyönüm, G., Yildirim, R. Water gas shift activity of AueRe catalyst over microstructured cordierite monolith wash-coated by ceria. International Journal Of Hidrogen Energy, 41, 5513-5521 (2016). https://doi.org/10.1016/j.ijhydene.2016.02.025

Resende, K., Teles, C., Jacobs, G., Davis, B., Cronauer, D., Kropf, A., Marshall C., Hori C., Noronha, F. Hydrodeoxygenation of phenol over zirconia supported Pd bimetallic catalysts. The effect of second metal on catalyst performance. Applied 
Catalysis B: Environmental, 232, 213-231 (2018). https://doi.org/10.1016/j.apcatb.2018.03.041

Sedjame, H.-J., Rachid Brahmi, R., Lafaye, G., Barbier Jr., J., Fontaine, C. Influence of the formulation of catalysts deposited on cordierite monoliths for acetic acid oxidation. Comptes Rendus Chimie, 21, 182-193 (2018). https://doi.org/10.1016/j. crci.2017.08.004

Şem, M., Emiroğlu, A., Çelik, M., $\mathrm{CO}$ and $\mathrm{C}_{3} \mathrm{H}_{8}$ oxidation activity of $\mathrm{Pd} / \mathrm{ZnO}$ nanowires/ cordierite catalyst. Applied Thermal Engineering, 99, 841-845 (2016). https://doi.org/10.1016/j. applthermaleng.2016.01.134

Tang, L., Zhao, Z., We, Y., Liu, J., Peng, Y., Li, K. Study on the coating of nano-particle and 3DOM $\mathrm{LaCoO}_{3}$ perovskite-type complex oxide on cordierite monolith and the catalytic performances for soot oxidation: The effect of washcoat materials of alumina, silica and titania. Catalysis Today, 297, 131-142 (2017). https://doi.org/10.1016/j. cattod.2017.06.016

Xu, Y. P., Qi, W.-K., Yang, X., Tang, Y., Wa, P., Fisher, A. Chemical removal of nitrate from water by aluminum-iron alloys. Chemosphere, 166, 197-202 (2017). https://doi.org/10.1016/j. chemosphere.2016.09.102

Yuan, E., Wu, C., Hou, X., Dou, M., Liu, G., Li, G., Wanga, L. Synergistic effects of second metals on performance of $(\mathrm{Co}, \mathrm{Ag}, \mathrm{Cu})$-doped $\mathrm{Pd} / \mathrm{Al}_{2} \mathrm{O}_{3}$ catalysts for 2-ethyl-anthraquinone hydrogenation. Journal of Catalysis, 34, 779-88 (2017). https://doi. org/10.1016/j.jcat.2017.01.003

Yuan, J., Zhao, K., Cai, T., Gao, Z., Yang, L., He, D. One-step dip-coating of uniform $\gamma$ - $\mathrm{Al}_{2} \mathrm{O}_{3}$ layers on cordierite honeycombs and its environmental applications. Ceramics International, 42, 14384-14390 (2016). https://doi.org/10.1016/j. ceramint.2016.06.003
Zabala, M., Martínez, S., Manzano, M., Vives, L. Groundwater chemical baseline values to assess the Recovery Plan in the Matanza-Riachuelo River basin, Argentina. Science of the Total Environment 541, 1516-1530 (2016). https://doi.org/10.1016/j. scitotenv.2015.10.006

Zhang, X., Wu, D., Ceramic monolith supported MnCe-M ternary mixed-oxide $(\mathrm{M}=\mathrm{Cu}$, Ni or $\mathrm{Co})$ catalyst for VOCs catalytic oxidation. Ceramics International, 42, 16563-16570 (2016). https://doi. org/10.1016/j.ceramint.2016.07.076

Zhai, Y., Zhao, X., Teng, Y., Li, X., Zhang, J., Wu, J., Zuo, R. Groundwater nitrate pollution and human health risk assessment by using HHRA model in an agricultural area. Ecotoxicology and Environmental Safety, 137, 130-142 (2017). https://doi.org/10.1016/j.ecoenv.2016.11.010

Zhuang, H.-D., Bai, S.-F., Liu, X.-M., Yam, Z.-F. Structure and performance of $\mathrm{Cu} / \mathrm{ZrO}$ catalyst for the synthesis of methanol from $\mathrm{CO}_{2}$ hydrogenation. Journal of Fuel Chemistry and Technology, 38, 462-467 (2010). https://doi.org/10.1016/S18725813(10)60041-2

Zoppas, F. M., Marchesini, F. A., Devard, A., Bernardes, A. M., Miró, E. E. Controlled deposition of Pd and In on carbon fibers by sequential electroless plating for the catalytic reduction of nitrate in water. Catalysis Communications, 78, 59-63 (2016). https://doi.org/10.1016/j.catcom.2016.02.012

Zoppas, F., Bernardes, A., Miró, E., Marchesini, F. Improving selectivity to dinitrogen using Palladium-Indium coated on activated carbon fibers: Preparation, characterization and application in water-phase nitrate reduction using formic acid as an alternative reductant source. Journal of Environmental Chemical Engineering, 6, 4764-4772 (2018). https://doi.org/10.1016/j. jece.2018.07.015 
